\title{
Medical Expert System- A Comprehensive Review
}

\author{
Rimpy Nohria \\ M.Tech Student \\ Department of Computer Science \& Engineering \\ DAV Institute of Engineering and Technology, Jalandhar, India
}

\begin{abstract}
Diseases must be treated healthy and on time. If they are not treated lying on time, they can escort to many health problems with these problems might become the reason of death. These problems are becoming inferior due to the scarcity of specialists, health facilities and practitioners. In an attempt to address such problems, studies ended attempts toward design and develop expert systems which can present advice for physicians and patients to make easy the diagnosis along with recommend treatment of patients. This review paper represents a comprehensive study of medical expert systems used for diagnosis of various diseases. It provides a concise overview of medical diagnostic expert systems along with presents an analysis of already existing studies.
\end{abstract}

\section{General Terms}

Artificial intelligence, Knowledge base, Expert system.

\section{Keywords}

Diagnosis, Symptoms, Patient, Facts, Rules.

\section{INTRODUCTION}

Artificial Intelligence is described as brainpower exhibited via an artificial unit. It is a separation of computer science dealing through sharp behavior, knowledge. Research in artificial intelligence is concerned with producing appliances to computerize jobs requiring pointed actions. Some authors also identify Artificial Intelligence as "The study along with design of intelligent agents, where intelligent agent is an organization that perceives its environment and acquires actions that maximize its chances of victory". These systems are used in economics, medicines and military. Examples comprise capability to answer diagnostic and user question, speech and facial recognition [8]. Artificial intelligence is separated into two categories. These two categories are conventional artificial intelligence and computational intelligence. Conventional artificial intelligence includes machine learning and stastical analysis. Computational artificial intelligence includes neural networks and fuzzy systems. The other applications of artificial intelligence are automation, computer vision, artificial creativity, expert system and knowledge management [12].

The remaining paper is arranged as: Section 2 provides a brief introduction to Expert System, Fuzzy expert system, artificial neural network and neuro-fuzzy technique. Section 3 discuss introduction to medical expert system and medical knowledge. Section 4 depicts the structure of medical expert system. Section 5 provides the related work and a comparative analysis of existing studies. Finally, the conversation is concluded in Section 6 .

\section{EXPERT SYSTEM}

Expert System is one of the most frequent applications of artificial intelligence. It is a set of programs to manipulate knowledge to solve problems within a specialized domain that necessitates human expertise. An expert system is also called knowledge based system. It is a computer curriculum that contains several of the subject specific information of one or more human experts. Normally, such a system includes a knowledge base containing accumulated experience as well as a set of rules used for applying the knowledge base to every particular situation. The most important features of expert system are user interface, data representation, inference, explanations and advantages of expert system are fast response, increased reliability, reduced cost, reducing errors, multiple expertise, intelligent database, reduced danger. There are moreover some disadvantages of expert system. Disadvantages are absence of common sense, no response in exceptional cases, and no change with changing environment.

A Fuzzy Expert System is a collection of membership functions plus rules. These functions and rules are used to reason regarding data. Fuzzy expert systems are leaning toward numerical processing. It receives numbers as input, and after that translates the input numbers into linguistic terms like Small, Medium and large. This adaptation is called fuzzification. Then the task of Rules is to map the input linguistic terms onto similar linguistic terms that concerning the output. This task is done by fuzzy Inference engine. Finally, the translation of output linguistic terms keen on an output number is done [5]. This conversion is called defuzzification. All the fuzzy rules and linguistic variables are stored in fuzzy knowledge base. Fuzzy expert systems have the capability to deal with inaccurate information.

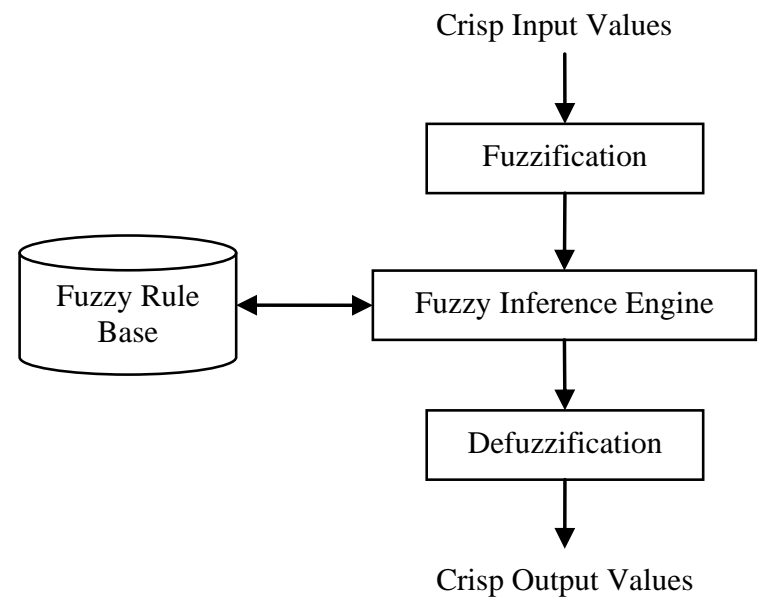

Fig. 1: Fuzzy Expert System [13]

Artificial Neural Network presents a flexible along with powerful tool to help doctors to appreciate complex clinical data across an extensive variety of medical applications. It used in medical diagnosis and health care application since of their predictive influential classifier for tasks, fault tolerance, generalization, in addition to learning from environment. An artificial neural network is a computational model to facilitate tries to report used for the parallel nature of the personality brain. An artificial neural network is an agreement of 
extremely interconnecting processing elements working in parallel. These elements are stimulated by biological anxious systems. As in environment, the connections among basics largely find away the network occupation. A subgroup of processing ingredient is called a layer within the network. The primary layer is the input layer and the final layer is the output layer. Between the input and output layer, there may be extra layers, called hidden layers. There is no limitation on deciding the number of hidden layer. The number of neurons in a layer and the number of layers depends on the complexity of the system studied [16].

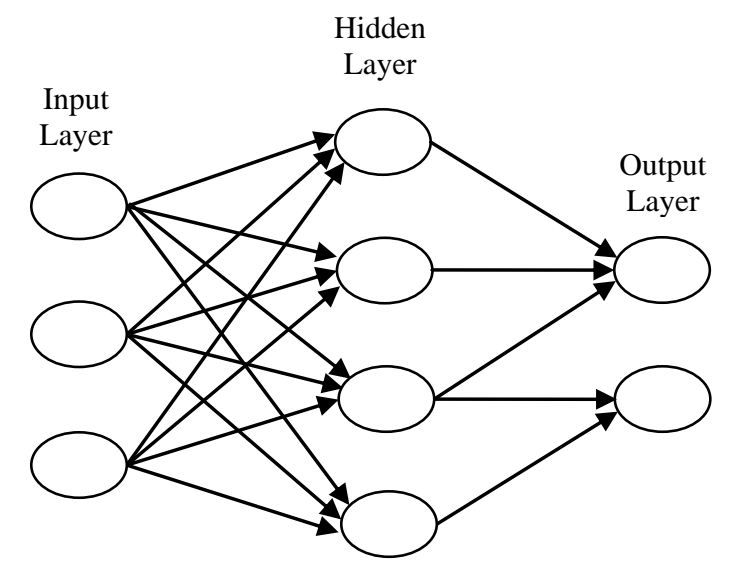

Fig. 2: Neural Network [16]

Adaptive neuro-fuzzy inference system is multi-layer system, facilitates to increase the performance by integrates the best features of Artificial Neural Networks and Fuzzy inference system into a single framework. It is a popular framework meant for solving complex problems. It is extremely competent system for solving the distracted equations involving the automatic knowledge expressed only by the if-then rules. It has advantages over the fuzzy expert system are: automatic adapts the non-linear connections between inputs and outputs also it has more accurate performance shown by testing the results [10].

\section{MEDICAL EXPERT SYSTEM}

The major aim of any medical expert system is the diagnosis and treatment of that disease. A huge outline of expert systems is medical. A medical expert system is built up of programs and medical knowledge base which gathered by computer. The information obtained from computer is similar to the information given by physician or expert in that particular area [12].

Medical Knowledge needs to be updated any time through new symptoms and diseases also knowledge of specialized physician is vital for the expansion of medical expert system. This knowledge is collected in two phases. In the first phase, the medicinal conditions of diseases are evidenced during the formation of personal convention with physician and patients. In the second phase, a deposit of rules is appearance where each rule contains IF part to contain the symptoms in addition to THEN part to have the disease that should be realized [7]

\section{THE STRUCTURE OF MEDICAL EXPERT SYSTEMS}

A medical expert system has the following components-

The Knowledge Base includes information through reference to diseases which are symbolized as a set of if-then production rules. The knowledge base is analogue to the long-standing individual memory. The entire sorting of production rules is organized in the knowledge base.

Consider the following example:

Sarcoidosis is a disease whose symptoms are dry cough, shortness of breath, mild chest pain, scaly rash, and fever, red bumps on legs, sore eyes and swollen ankles. So it will be accumulated in knowledge base in the appearance of a rule which is as follow:-

Disease (Patient, sarcoidosis):-

Symptom (Patient, dry_cough),

Symptom (Patient, shortness_of_breath),

Symptom (Patient, mild_chest_pain),

Symptom (Patient, scaly_rash),

Symptom (Patient, fever),

Symptom (Patient, red_bumps_on_legs),

Symptom (Patient, sore_eyes),

Symptom (Patient, swollen_ankles).

Fig. 3: Production Rule in Knowledge Base

Similarly in this technique we have store maximum probable rules in the knowledge base.

2) The Fact Base contains facts which are utilized to match adjacent to the antecedent part of rules accumulated in the knowledge base. The fact base is analogue to the short term human memory.

3) The main assignment of Inference Engine is to take out the reasoning by linking the rules with facts and deducing new facts.

4) The User Interface is employ to communicate between user and expert system. It is the technique by which the expert system interacts through the user.

5) The Explanation Module authorizes the user to request the expert system how a particular conclusion is reached and why a specific fact is aspiration.

6) The Developer Interface is used to revise the knowledge base.

\section{RELATED WORKS}

The Medical diagnostic Systems comprise undergone lots of changes and are using innovative techniques to generate enhanced results. This section momentarily summarizes some of the rule based; fuzzy expert system and artificial neural network based medical diagnostic systems in addition to presents a comparative analysis of different existing studies in table 4.

Hossain, M.S, Khalid, M.S, Akter, S, Dey, S [14] design, development and application of an expert system for diagnosis of influenza under uncertainty. The recently developed general belief rule-based inference method by using the evidential reasoning (RIMER) approach is in use to develop this system, termed as Belief Rule Based Expert System (BRBES). This approach preserve handle different types of uncertainties, together in knowledge representation, plus in inference procedures. Symptoms of this disease are considered as inputs to system are cough, fever, headache, bireme, nasal congestion, nasal polyps and sinusitis. The knowledge-base was constructed by using evidences of the 
real patient data along through in discuss with the Influenza specialists of Bangladesh. Validate the BRBES by using the practical case studies. This system generated results are effective with reliable than manual system in terms of accuracy.

Azian Azamimi Abdullah, Zulkarnay Zakaria, Nur Farahiyah Mohammad [9] proposed a Fuzzy expert system for diagnosis of the risk of hypertension patients for patients aged between 20 's, 30's and 40's years as well as is divided into male and female gender. Data set are acquired from 10 people which consists of male \& female with dissimilar background and input parameters used for this system are age, body mass index, blood pressure and heart rate. In diagnosis process, linguistic variables and their membership functions are based on medical experts knowledge. This proposed system can provide a cheaper and more accurate result then other techniques for diagnosis of blood pressure i.e. hypertension. The classification of input variables in this expert system as follow:-

Table 1: Classification of Input Variables [9]

\begin{tabular}{|c|c|c|}
\hline $\begin{array}{c}\text { Input } \\
\text { Variable }\end{array}$ & Range & Fuzzy Sets \\
\hline \multirow{4}{*}{ Age } & $<25$ & Young \\
\cline { 2 - 3 } & $20-40$ & Middle \\
\cline { 2 - 3 } & $36>$ & Old \\
\hline \multirow{4}{*}{ BP } & $<110 / 70$ & Low \\
\cline { 2 - 3 } & $110 / 70-140 / 90$ & Normal \\
\cline { 2 - 3 } & $139 / 89>$ & High \\
\hline \multirow{3}{*}{ BMI } & $<18$ & Low \\
\cline { 2 - 3 } & $19-25$ & Medium \\
\cline { 2 - 3 } & $>25$ & High \\
\hline \multirow{3}{*}{ Heart Rate } & $<90$ & Low \\
\cline { 2 - 3 } & $75-115$ & Medium \\
\cline { 2 - 3 } & $100>$ & High \\
\hline
\end{tabular}

Komal R. Hole, Vijay S. Gulhane [15] present a rule-based expert system for memory loss disease by the help of rules and facts. For saving the cases Case-based approach is used and compared with previously saved cases. This paper initially discusses diverse approaches in designing of medical expert systems by focus on all the information concerning the memory loss. This system will assist the patients to obtain the advice about the different disorders assault to them due to their nervous system disorders. It is an attempt to center on some of extremely important diseases related to memory. Expert rules developed on symptoms of every type of neurological disease and presented by decision tree also inferred with forward-chaining method. The knowledge base is collected from books and doctors that contain information about memory loss and all its related diseases.

Neshat, M, Yaghobi, M, Naghibi, M.B, Esmaelzadeh, A [5] designed a fuzzy system for learning, analysis and diagnosis of liver disorders. In this work, data has been selected from trusty database (UCI) that has 345 records and 6 fields as the entry parameters and rate of liver disorder risks is worn as the system resulting. All the standardization methods within medical diagnosis, a correct diagnosis is immobile considered to be an art much of this situation is for, to medical diagnosis needs ability as well as experience in dealing through uncertainty. This system is compared with other traditional diagnostic systems. This fuzzy system can be helpful to a specialist assistant or for training medication students. This system is faster, cheaper, and also more liable and more accurate also a specialist assistant or for training medicine students. The verification on time diagnosis and appointing the rate of liver disorders improvement is $91 \%$.

Noura Ajam [16] attempt has make to use of Artificial Neural network for diagnosis of heart disease. Feed-forward back propagation neural network is utilized as a classifier to differentiate between absence and presence of disease. This network consists of input layer with 13 neuron, a hidden layer with 20 neuron and an output layer with just 1 neuron. The number of neurons in the hidden layer is deciding on using test and error method. The data were collected from UCI machine learning repository to diagnose the disease. The goal for the neural network will be classified with 0's as absence disease moreover with 1's as presence disease. The result shows that the performance of this network is $88 \%$ of cases in testing set. The analysis attributes of dataset used in this study are shown as follow:-

Table 2: Diagnosis Attributes of dataset [16]

\begin{tabular}{|c|c|}
\hline \multicolumn{2}{|c|}{ Diagnosis Attribute Name } \\
\hline Age & \\
\hline Sex & $(\mathrm{M}=1)(\mathrm{F}=0)$ \\
\hline Chest pain type & $\begin{array}{l}\text {--Value 1: Typical Angina } \\
\text {--Value 2: Atypical Anginal } \\
\text {--Value 3:Non-Anginal Pain } \\
\text {--Value 4: Asymptotic }\end{array}$ \\
\hline $\begin{array}{l}\text { Resting Blood } \\
\text { Pressure }\end{array}$ & \\
\hline Cholesterol & \\
\hline $\begin{array}{c}\text { Fasting Blood } \\
\text { Sugar }\end{array}$ & $(1=$ true; $0=$ false $)$ \\
\hline Resting ECG & $\begin{array}{l}\text {--Value 0: Normal } \\
\text {--Value 1: having ST-T wave } \\
\text { abnormality } \\
\text {--Value 2: Showing Probable or } \\
\text { definite left ventricular Hypertrophy } \\
\text { by Estes' criteria }\end{array}$ \\
\hline $\begin{array}{l}\text { Maximum Heart } \\
\text { Rate }\end{array}$ & \\
\hline $\begin{array}{l}\text { Exercise induced } \\
\text { rate }\end{array}$ & $(1=$ yes; $0=$ no $)$ \\
\hline Number of Vessels & $--(0-3)$ \\
\hline
\end{tabular}




\begin{tabular}{|c|c|}
\hline Colored & \\
\hline Slop & $\begin{array}{l}\text {--Value 1: Up Sloping } \\
\text {--Value 2: Flat } \\
\text {--Value 3: Down Sloping }\end{array}$ \\
\hline $\begin{array}{l}\text { Tha } 1 \text { Normal, } \\
\text { Fixed defect, } \\
\text { Reversible defect }\end{array}$ & $--3,6,7$ \\
\hline
\end{tabular}

Maitri Patel, Atul Patel, Paresh Virparia [11] proposed a web based expert system for diagnosis of viral infections. A rule based expert system present consultation along with analysis is more beneficial while used through web based applications. Most important focus is made on practice of technology by the current inventions is made, to benefit the community in over all wellbeing. Prescriptions to these infections canister are deduced through this system, which are accurate as well as many medical practitioners and knowledge has been employ to develop the knowledge base.

E. Bursuk, M. Ozkan, B. Llerigelen [2] establish a medical expert system for diagnosis of cardiological diseases. This medical system will be practical for both patients and physicians and is developed by using a community domain rule based expert system. In this fact and rules symbolize expert and reference book's knowledge. For program's inference engine a cardiological disease tree is formed and it has "yes" or "no" answers to questions. The database contains the thirteen diseases. The valuation of this program is complete by twenty-five patient information. Proposed system results are compatible with physician's diagnoses.

S Ali, P Chia, K Ong [3] present an automatic delivery system for clinical guidelines (DSCG) to supports clinicians in diagnosing and treating patients tolerate from chest pain in the emergency division. This system obtains patient data, such as illness and assessment results, as well as matches these data with eligibility criteria. Strategies are adaptively chosen from a knowledge base server that has records of clinically defined, graphical strategy. It recommends the majority favorable treatment arrangements and analysis based on the nearly all feasible diagnosis. Clinicians might either use the commendations as a suggestion or trigger an assortment to check the patient's condition during the cure with an intelligent agent.

Md. S. Hossain, K. Andersson, S. Naznin [17] developed an expert system for diagnosis of measles under uncertainty. A belief rule-based inference methodology using evidential reasoning approach (RIMER) can be used for developing the system, which is able of handling various types of uncertainties. Measles is usually diagnosed from its signs and symptoms via a physician, which cannot be deliberate with $100 \%$ confidence during the diagnosis procedure. This proposed system results has been compared with the expert estimation and with a Fuzzy Logic based system. In both experimental cases, it has been establish that the Belief Rule Based Expert, is more reliable and accurate.

B. Prasad, H. Wood, J. Greer, G. McCalla [1] presents a knowledge-based system for training student physicians to diagnose bronchial asthma. This system uses a case-based instruction method where the student learns how to diagnose disease through practice on carefully selected cases. The conversation is completely prohibited by the student, who canister use his/her own language in converse with the system. Entrenched in the tutoring system is an expert diagnostician for bronchial asthma, which is called ahead to evaluate the student's attempted diagnosis. The system is completely implemented, has been tested through actual physicians, and is currently organism field tested with physicians and residents in interior medicine. Initial suggestions imply that the methodologies urbanized for this knowledge-based tutoring system will relate beyond the bronchial asthma domains.

Solomon Gebremariam [6] build up a prototype self-learning knowledge-based system that preserve offer advice meant for physicians and patients toward assist the diagnosis plus cure of diabetic patients. Knowledge is collected using both structured and unstructured consultations from domain experts which are chosen with purposive sampling technique as of Black Lion Hospital Diabetes Center. It transports into play backward chaining which instigates with possible solutions and tries toward assemble information to facilitate verifies the result. The universal total performance of the prototype system is $84.2 \%$. The evaluation taken in this expert system are shown as:-

Table 3: Decision taken in Expert System [6]

\begin{tabular}{|c|c|c|}
\hline \multicolumn{2}{|c|}{ Symptoms } & Result \\
\hline \multicolumn{2}{|c|}{ Non Related Symptoms } & $\begin{array}{c}\text { Less Likely to } \\
\text { have Diabetes }\end{array}$ \\
\hline $\begin{array}{c}\text { Related } \\
\text { Symptoms }\end{array}$ & $\begin{array}{c}\text { Lab Result using } \\
\text { FPG 100-125 } \\
\mathrm{mg} / \mathrm{dL}\end{array}$ & Prediabetes \\
\hline $\begin{array}{c}\text { Related } \\
\text { Symptoms }\end{array}$ & $\begin{array}{c}\text { Lab Result using } \\
\text { FPG }<99 \mathrm{mg} / \mathrm{dL}\end{array}$ & Diabetes Free \\
\hline $\begin{array}{c}\text { Related } \\
\text { Symptoms }\end{array}$ & $\begin{array}{c}\text { Lab Result using } \\
\text { FPG }>126 \mathrm{mg} / \mathrm{dL}\end{array}$ & $\begin{array}{c}\text { Type 1/ Type 2/ } \\
\text { other Diabetes } \\
\text { type }\end{array}$ \\
\hline
\end{tabular}

F. Ibrahim, J.B. Ali, A.F. Jaais, M.N. Taib [4] describes a knowledge-based system employing expert system rules to perceive different kinds of eye diseases. This system the types of eye diseases can he detected. Most frequent eye diseases contaminate the Malaysian population. This project was designed and programmed through the object-oriented expert system shell EXSYS. The rules were developed based on the symptoms of every type of eye disease, and were presented via tree-graph forward-chaining through a depth-first search method. In organize to enhance user interaction through the system, graphical user interfaces be employed. This paper present expert system is able to perceive and give early diagnosis of five types of eye diseases including senile, secondary, open-angle, acute, allergic and infectious diseases.

Bekaddour Fatima, Chikh Mohammed Amine [10] summarizes an approach for recognizing breast cancer diagnosis by using adaptive neuro-fuzzy inference system. Computer assisted diagnosis preserve be helpful for doctors within detection and diagnosing of potential abnormalities. Wisconsin breast cancer diagnosis database used to evaluate this model is developed at University of California, Irvine. Experimental results are show that this model has better performance than other cited in literature. The performance of the model is 98.25 accurate. 
Table 4: Comparison of Existing Studies on Medical Expert System

\begin{tabular}{|c|c|c|c|c|}
\hline Reference & Technique Used & $\begin{array}{c}\text { Disease } \\
\text { Diagnosed }\end{array}$ & Inputs to Technique & Remarks \\
\hline $\begin{array}{l}\text { Hossain, M.S, Khalid, } \\
\text { M.S, Akter, S, Dey, S } \\
\text { [14] }\end{array}$ & $\begin{array}{l}\text { Rule Based Expert } \\
\text { System }\end{array}$ & Influenza Disease & $\begin{array}{l}\text { Real patients data are } \\
\text { collected by consulting } \\
\text { the Influenza specialists } \\
\text { of Bangladesh, Disease } \\
\text { Symptoms }\end{array}$ & $\begin{array}{l}\text { This system is developed by using } \\
\text { rule-based inference method of } \\
\text { evidential reasoning and handle } \\
\text { different types of uncertainties. } \\
\text { Validate the system by using the } \\
\text { practical case studies and shows } \\
\text { that system results are effective } \\
\text { than manual system. }\end{array}$ \\
\hline $\begin{array}{l}\text { Azian Azamimi } \\
\text { Abdullah, Zulkarnay } \\
\text { Zakaria, Nur } \\
\text { Farahiyah } \\
\text { Mohammad [9] }\end{array}$ & $\begin{array}{l}\text { Fuzzy Expert } \\
\text { System }\end{array}$ & $\begin{array}{l}\text { Hypertension } \\
\text { Disease }\end{array}$ & $\begin{array}{l}\text { Age, Gender, Blood } \\
\text { pressure, Body mass } \\
\text { index and heart rate }\end{array}$ & $\begin{array}{l}\text { This system is used to diagnosis of } \\
\text { hypertension for patient's divided } \\
\text { between aged and gender. } \\
\text { Experimental results shown that } \\
\text { this system is more accurate than } \\
\text { other traditional methods. }\end{array}$ \\
\hline $\begin{array}{l}\text { Komal R. Hole, Vijay } \\
\text { S. Gulhane [15] }\end{array}$ & $\begin{array}{l}\text { Rule Based Expert } \\
\text { System }\end{array}$ & $\begin{array}{l}\text { Memory Loss } \\
\text { Disease }\end{array}$ & Disease Symptoms & $\begin{array}{l}\text { The developed system based on } \\
\text { rules and helps patients patients to } \\
\text { obtain the advice about the different } \\
\text { disorders. The knowledge base } \\
\text { collects information from books } \\
\text { and doctors about neurology and its } \\
\text { disorders. }\end{array}$ \\
\hline $\begin{array}{l}\text { Neshat, M, Yaghobi, } \\
\text { M, Naghibi, M.B, } \\
\text { Esmaelzadeh, A [5] }\end{array}$ & $\begin{array}{l}\text { Fuzzy Expert } \\
\text { System }\end{array}$ & Liver Disorders & $\begin{array}{l}\text { Data gathered from } \\
\text { trusty database, } 6 \\
\text { entrance parameters of } \\
\text { liver disorders }\end{array}$ & $\begin{array}{l}\text { This fuzzy system can be helpful to } \\
\text { a specialist assistant or for training } \\
\text { medication students for diagnosis of } \\
\text { liver disorders. The system } \\
\text { verification on time diagnosis and } \\
\text { appointing the rate of liver } \\
\text { disorders is } 91 \% \text {. }\end{array}$ \\
\hline Noura Ajam [16] & $\begin{array}{l}\text { Artificial Neural } \\
\text { network }\end{array}$ & Heart Disease & Disease Symptoms & $\begin{array}{c}88 \% \text { accuracy is achieved in } \\
\text { diagnosis of heart disease by using } \\
\text { feed forward back propagation } \\
\text { neural network. }\end{array}$ \\
\hline $\begin{array}{c}\text { Maitri Patel, Atul } \\
\text { Patel, Paresh Virparia } \\
\text { [11] }\end{array}$ & $\begin{array}{l}\text { Rule Based Expert } \\
\text { System }\end{array}$ & Viral Infection & Disease Symptoms & $\begin{array}{l}\text { This system hass most important } \\
\text { focus is made on practice of } \\
\text { technology by the current } \\
\text { inventions is made, to benefit the } \\
\text { community in over all wellbeing. } \\
\text { Prescriptions to these infections } \\
\text { canister are deduced through this } \\
\text { system, which are accurate as well } \\
\text { as many medical practitioners. }\end{array}$ \\
\hline Reference & Technique Used & $\begin{array}{c}\text { Disease } \\
\text { Diagnosed }\end{array}$ & Inputs to Technique & Remarks \\
\hline $\begin{array}{l}\text { E. Bursuk, M. Ozkan, } \\
\text { B. Llerigelen [2] }\end{array}$ & $\begin{array}{c}\text { Knowledge Based } \\
\text { System }\end{array}$ & $\begin{array}{l}\text { Cardiological } \\
\text { Diseases }\end{array}$ & Disease Symptoms & $\begin{array}{l}\text { This proposed medical expert } \\
\text { system will be practical for both } \\
\text { patients and physicians for } \\
\text { providing decision of disease. } \\
\text { Twenty-five patient's information } \\
\text { can be used to valuation of the } \\
\text { expert system. }\end{array}$ \\
\hline $\begin{array}{l}\text { S Ali, P Chia, K Ong } \\
\text { [3] }\end{array}$ & $\begin{array}{c}\text { Knowledge Based } \\
\text { System }\end{array}$ & Chest Pain & $\begin{array}{l}\text { Data obtained from } \\
\text { Laboratory } \\
\text { examinations, } \\
\text { Ultrasound, Chest X- } \\
\text { Ray images, Narrative } \\
\text { texts describing the }\end{array}$ & $\begin{array}{l}\text { This expert system distributes } \\
\text { appropriate clinical strategy and is } \\
\text { finalized for pilot trial on the } \\
\text { accidents and emergency } \\
\text { department of the national } \\
\text { university hospital. No } \\
\text { experimental results of this expert }\end{array}$ \\
\hline
\end{tabular}




\begin{tabular}{|c|c|c|c|c|}
\hline & & & patient's condition & system are found. \\
\hline $\begin{array}{c}\text { Md. S. Hossain, K. } \\
\text { Andersson, S. Naznin } \\
\text { [17] }\end{array}$ & $\begin{array}{c}\text { Rule Based Expert } \\
\text { System }\end{array}$ & Measles Disease & Disease Symptoms & $\begin{array}{l}\text { This rule based expert system detect } \\
\text { the measles under uncertainty using } \\
\text { evidential reasoning approach. } \\
\text { Experimental results shows that } \\
\text { proposed system is more reliable } \\
\text { and accurate. }\end{array}$ \\
\hline $\begin{array}{l}\text { B. Prasad, H. Wood, } \\
\text { J. Greer, G. McCalla } \\
\text { [1] }\end{array}$ & $\begin{array}{c}\text { Knowledge Based } \\
\text { System }\end{array}$ & $\begin{array}{c}\text { Bronchial Asthma } \\
\text { Disease }\end{array}$ & Disease Symptoms & $\begin{array}{l}\text { This expert system helps student } \\
\text { learns how to diagnose bronchial } \\
\text { asthma through practice on } \\
\text { carefully selected cases and has } \\
\text { been tested through actual } \\
\text { physicians, and is currently } \\
\text { organism field tested with } \\
\text { physicians and residents in interior } \\
\text { medicine. }\end{array}$ \\
\hline $\begin{array}{c}\text { Solomon } \\
\text { Gebremariam [6] }\end{array}$ & $\begin{array}{c}\text { Rule Based Expert } \\
\text { System }\end{array}$ & Diabetes Disease & $\begin{array}{l}\text { Disease Symptoms, Lab } \\
\text { test results, Age, } \\
\text { obesity, family history, } \\
\text { Ketone }\end{array}$ & $\begin{array}{l}\text { This system presents advice toward } \\
\text { physicians and patients to help the } \\
\text { diagnosis and treatment of diabetes. } \\
\text { The Performance of the system is } \\
84.2 \% \text {. }\end{array}$ \\
\hline $\begin{array}{l}\text { F. Ibrahim, J.B. Ali, } \\
\text { A.F. Jaais, M.N. Taib } \\
\text { [4] }\end{array}$ & $\begin{array}{c}\text { Knowledge Based } \\
\text { System }\end{array}$ & Eye Disease & Disease Symptoms & $\begin{array}{l}\text { This expert system gives advice } \\
\text { about types of eye disease found in } \\
\text { Malaysia and no experimental } \\
\text { results are shown. }\end{array}$ \\
\hline $\begin{array}{l}\text { Bekaddour Fatima, } \\
\text { Chikh Mohammed } \\
\text { Amine [10] }\end{array}$ & $\begin{array}{l}\text { Adaptive Neuro- } \\
\text { Fuzzy Inference } \\
\text { System }\end{array}$ & $\begin{array}{l}\text { Breast Cancer } \\
\text { Disease }\end{array}$ & Disease Symptoms & $\begin{array}{l}\text { This system assisted diagnosis can } \\
\text { be helpful for doctors in detection } \\
\text { and diagnosing of potential } \\
\text { abnormalities. The performance of } \\
\text { model is } 98.25 \% \text {. }\end{array}$ \\
\hline
\end{tabular}

\section{CONCLUSIONS}

This review paper expresses different expert systems during medical diagnosis and evaluates the contributions through by different researchers. Some researchers have estimated their medical expert systems in hospitals commencing the experts and retrieved a variety of parameters like accuracy and sensitivity. Using these parameters, they have estimated the performance of their expert systems. The accuracy along with other parameters of expert system depends on the knowledge base that has relevant knowledge. There should be anxiety on knowledge acquisition, a stage during which knowledge is collected. So performance of expert system depends on every one of these factors. One can enlarge the performance of expert system via making knowledge base more accurate and extremely little work is done using neuro-fuzzy, ANN and fuzzy logic within medical diagnosis. So we will go used for these in medical diagnosis.

\section{REFERENCES}

[1] B. Prasad, H. Wood, J. Greer, G. McCalla, "A knowledge-based system for tutoring bronchial asthma diagnosis" proceedings of Second Annual IEEE Symposium on Computer-Based Medical Systems 1989 IEEE.

[2] E. Bursuk, M. Ozkan, B. Llerigelen, "A medical expert system in cardiological diseases" proceedings of Engineering in Medicine and Biology twenty first Annual Conference and the 1999 Annual Fall Meetring of the Biomedical Engineering Society 1999 IEEE.
[3] S Ali, P Chia, K Ong, "Graphical Knowledge - Based Protocols for Chest Pain Management" proceedings of the Computers in Cardiology 1999 IEEE.

[4] F. Ibrahim, J.B. Ali, A.F. Jaais, M.N. Taib, "Expert system for early diagnosis of eye diseases infecting the Malaysian population", proceedings of IEEE Region tenth International Conference on Electrical and Electronic Technology TENCON 2001 IEEE.

[5] Neshat, M, Yaghobi, M, Naghibi, M.B, Esmaelzadeh, A, "Fuzzy Expert System Design for Diagnosis of Liver Disorders" proceedings of Knowledge Acquisition and Modeling, KAM eighth International Symposium 2008 IEEE.

[6] Solomon Gebremariam, "A Self Learning Knowledge Based System for Diagnosis and Treatment of Diabetes", Master's thesis, Addis Ababa University, Ethiopia.

[7] Samy S. Abu Naser, Abu Zaiter A. Ola, "An Expert System for Diagnosing Eye Diseases Using CLIPS", Journal of Theoretical and Applied Information Technology, pp. 923-930, 2005-2008 JATIT.

[8] Eugena Roventa, George Rosu, "The Diagnosis of Some Kidney Diseases in a PROLOG Expert System", proceedings of the third international workshop on Soft Computing Applications 2009 IEEE.

[9] Azian Azamimi Abdullah, Zulkarnay Zakaria, Nur Farahiyah Mohammad, "Design and Development of Fuzzy Expert System for Diagnosis of Hypertension", 
Second International Conference on Intelligent Systems, Modelling and Simulation 2011 IEEE.

[10] Bekaddour Fatima, Chikh Mohammed Amine, "A NEURO-FUZZY INFERENCE MODEL FOR BREAST CANCER RECOGNITION", International Journal of Computer Science \& Information Technology (IJCSIT), Vol. 4, No. 5, October 2012.

[11] Maitri Patel, Atul Patel, Paresh Virparia, "Rule Based Expert System for Viral Infection Diagnosis", International Journal of Advanced Research in Computer Science and Software Engineering, Vol. 3, Issue 5, May 2013.

[12] Jimmy Singla, "The Diagnosis of Some Lung Diseases in a PROLOG Expert System", International Journal of Computer Applications, vol. 78, no. 15, pp. 37-40, September 2013.

[13] A. Kaur and A. Bhardwaj, "Artificial Intelligence in Hypertension Diagnosis: A Review", International Journal of Computer Science and Information Technologies, Vol. 5(2), pp. 2633-2635, 2014.

[14] Hossain, M.S, Khalid, M.S, Akter, S, Dey, S., "A belief rule-based expert system to diagnose influenza", proceedings of Strategic Technology ninth International Forum 2014 IEEE.

[15] Komal R. Hole, Vijay S. Gulhane, "Rule-Based Expert System for the Diagnosis of Memory Loss Diseases", International Journal of Innovative Science, Engineering \& Technology, Vol. 1, Issue 3, May 2014.

[16] Noura Ajam, "Heart Disease Diagnosis using Artificial Neural Network", IISTE Network and Complex Systems, Vol. 5, No. 4, 2015.

[17] Md. S. Hossain, K. Andersson, S. Naznin, "A Belief Rule Based Expert System to Diagnose Measles under Uncertainty", Int'1 Conference Health Informatics and Medical Systems, HIMS' 15.

\section{AUTHOR PROFILE}

Rimpy Nohria received her B.Tech degree in Computer Science \& Engineering from North West Institute of Engg. \& Tech., Dhudhike, Moga, Punjab. She is currently pursuing M.Tech in Department of Computer Science \& Engineering from DAV Institute of Engineering \& Technology, Jalandhar, Punjab. Her area of interest includes Expert systems, fuzzy logic, Neuro-fuzzy; computer aided medical decision support systems 